\title{
Surface composition and near-surface hardness studies on high dose boron-implanted 304 stainless steel
}

\author{
A K GOEL, N D SHARMA*, R K MOHINDRA, \\ P K GHOSH ${ }^{1}$ and M C BHATNAGAR ${ }^{2}$ \\ Physics Department, Kurukshetra University, Kurukshetra 132119, India \\ ${ }^{1}$ Department of Mechanical and Industrial Engineering, University of Roorkee, Roorkee \\ 247667 , India \\ ${ }^{2}$ Thin Film Laboratory, Indian Institute of Technology, New Delhi 110016, India \\ MS received 5 January 1990; revised 25 July 1990
}

\begin{abstract}
The modification of boron-implanted near surface of 304 stainless steel having strained and strain-free surfaces was studied. The energy of the boron ion was $130 \mathrm{keV}$ at a dose of $2.5 \times 10^{17}$ ions $\mathrm{cm}^{-2}$. Ion-implantation is known to modify the tribological properties of metals, however, it is not well-understood as to how such a shallow implanted layer can affect the microhardening. A full understanding of the process involved is yet to emerge. In the present work the ion implanted layer was characterized for boron depth profiles using AES and XPS. The implanted layer is observed to contain $\mathrm{B}_{2} \mathrm{O}_{3}, \mathrm{Fe}_{2} \mathrm{~B}, \mathrm{FeB}$ and $\mathrm{CrB}_{2}$ compounds with small fractions of chromium and iron oxides. The strain-free surface of 304 SS shows an increase in microhardness by $\sim 80 \%$ after boron ion implantation at $2 \mathrm{gf}$ and the strained surface by $\sim 30 \%$ at the same load. The annealing effects on microhardness for mechanically polished and implanted samples were also investigated in the temperature range 100 to $400^{\circ} \mathrm{C}$. The possible correlation of near-surface microhardness increase with boride formation is discussed.
\end{abstract}

Keywords. $304 \mathrm{SS} ;{ }^{11} \mathrm{~B}^{+}$implantation; AES; XPS; microhardness.

\section{Introduction}

High-dose ion implantation $\left(1 \times 10^{16}\right.$ to $1 \times 10^{18}$ ions $\left.\mathrm{cm}^{-2}\right)$ improves the mechanical properties of metals and alloys. (Dearnaley 1985; Madakson 1985; Knystautas et al 1987; Goel et al 1988, 1989; Kluge et al 1989). Ion implantation allows a controlled dose of almost any element to be introduced into the near-surface target area. Usually the depth of ion penetration is several hundred nanometers. It has been observed that a $\gamma_{f c c}$ to $\alpha_{b c c}^{\prime}$ transformation is induced in austenitic stainless steels implanted with phosphorus, antimony or boron and the driving force for this transformation is the relief effected in the implanted layer experiencing high levels of stress caused by the accumulation of radiation damage (Johnson et al 1982, 1985; Raud et al 1989). This interpretation is supported by the observation of an $\alpha_{b c c}^{\prime}$ phase in helium-implanted austenitic 304 stainless steel (Hayashi and Takahashi 1982; Hayashi et al 1984).

We present here investigations of high dose boron ion-implantation on near-surface hardness of 304 stainless steel (SS) having different pre-implantation surface conditions. The surface condition of the substrate is either strained (produced by mechanical polishing) or strain-free (produced by chemical etching). The near-surface

\footnotetext{
*For correspondence
} 
hardness was measured using the Knoop microhardness tester and the annealing effects were also studied. The surface composition and boron depth profile were determined by Auger Electron Spectroscopy (AES) and the compound formation was studied using X-ray Photoelectron Spectroscopy (XPS).

\section{Experimental}

\subsection{Sample preparation}

Samples of size $26 \times 6 \mathrm{~mm}^{2}$ were taken from $1.3 \mathrm{~mm}$ thick type 304 stainless steel sheet. They were polished using levigated alumina powder of particle size $0.014 \mu \mathrm{m}$. Some of the specimens. after polishing. were suitably etched by using an etchant containing $10 \mathrm{ml} \mathrm{HNO}_{3}, 10 \mathrm{ml}$ acetic acid, $5 \mathrm{ml}$ glycerol and $15 \mathrm{ml} \mathrm{HCl}$ to remove the strained layer formed during mechanical polishing from the surface of the sample. All the polished and etched samples were cleaned ultrasonically in acetone, then benzene and finally in isopropanol.

\subsection{Ion implantation}

The samples were implanted for 3 hours under a vacuum of $2 \times 10^{-6}$ Torr with ${ }^{11} \mathrm{~B}^{+}$-ions accelerated to an energy of $130 \mathrm{keV}$ at a dose of $2.5 \times 10^{17}$ ions $\mathrm{cm}^{-2}$. The specimens were kept normal to the ion beam in the implanter (Varian DF-3000). The temperature during implantation was $\sim 300^{\circ} \mathrm{C}$ and was recorded using a thermocouple. The ion beam was electrostatically scanned over the entire surface at a beam current density of $3 \cdot 4 \mu \mathrm{A} \mathrm{cm}^{-2}$.

\subsection{AES analysis}

The depth profile of $\mathrm{B}, \mathrm{C}, \mathrm{O}, \mathrm{Fe}, \mathrm{Cr}$ and $\mathrm{Ni}$ in the implanted layer was examined using a Scanning Auger Microprobe (SAM-PHI Model 590A) combined with a 4-keV differentially pumped $\mathrm{Ar}^{+}$ion source for sputter etching. The ion beam current is kept at $\sim 300 \mu \mathrm{A} \mathrm{cm}^{-2}$ which provides a sputter rate of $\sim 125 \AA / \mathrm{min}$. Auger analysis was performed at $3 \mathrm{keV}$ beam voltage with a beam current of about $5 \mu \mathrm{A}$ on a scanned area of $160 \times 160 \mu \mathrm{m}^{2}$ with simultaneous sputtering. The peak to peak heights of each selected element are measured subsequently at various depths and stored in the computerised system. The presented data are in the form of relative atomic concentrations estimated from the peak to peak height.

\section{$2.4 X P S$ analysis}

XPS studies were made using a PHI Model No. 1800 with $\operatorname{MgK}_{\alpha}(1253.6 \mathrm{eV})$ radiation with a cylindrical mirror analyser. An ultra-high vacuum of $10^{-9}$ Torr was maintained throughout the measurements. The $\mathrm{Au}\left(4 f_{7 / 2}\right)$ line $(83.8 \mathrm{eV})$ was used for calibration. The overall resolution was $1 \cdot 2 \mathrm{eV}$ for pure $\mathrm{Ag}\left(3 d_{5 / 2}\right)$ at pass energy of $25 \mathrm{eV}$. XPS 
data have been recorded for $\mathrm{B}(1 s) . \mathrm{O}(1 s), \mathrm{Cr}(2 p), \mathrm{Fe}(2 p)$ and $\mathrm{Ni}(2 p)$ at plateau regions, where the maximum boron has been detected $(\sim 385 \mathrm{~nm})$.

\subsection{Microhardness measurements}

Microhardness was measured at room temperature using a Leitz-MM6 hardness tester fitted with a Knoop diamond pyramidal indenter, and was calculated using the equation

$$
\mathrm{KHN}=14230\left(P / d^{2}\right),
$$

where KHN is the Knoop microhardness $\left(\mathrm{kgf} / \mathrm{mm}^{2}\right), P$ is the applied load (gf) and $d$ is the long indentation diagonal of the indentation mark $(\mu \mathrm{m})$. Test loads from 2 to $50 \mathrm{gf}$ were applied for a dwell time of $35 \mathrm{~s}$. The indentation depth was calculated using the relation:

$$
\text { depth of indentation }=(1 / 30) \times \mathrm{d} \text {. }
$$

At least 10 measurements were made on each sample at every load and the average value was determined. Standard deviations from mean value were also calculated. The polished-implanted specimen was cut into four pieces and annealing treatments were carried out in air in laboratory ovens for four hours at $100,200,300$ and $400^{\circ} \mathrm{C}$.

\section{Results and discussion}

The optical micrograph in figure 1 shows the surface of a mechanically polished implanted specimen and Knoop indentation marks at 2, 5, 10, 25 and 50 gf. The micrograph also shows Vicker's indentation marks.

Figure 2 depicts \% atomic distribution for $\mathrm{B}, \mathrm{C}, \mathrm{O}, \mathrm{Ni}, \mathrm{Cr}$ and $\mathrm{Fe}$ in the implanted layer as measured by AES. The boron implantation profile in $304 \mathrm{SS}$ is about $750 \mathrm{~nm}$ deep and has a Gaussian-like distribution with a peak atomic concentration of $\sim 17$ at. $\%$ at $\sim 385 \mathrm{~nm}$. The high value of implantation depth profile and low peak atomic concentration of boron is possibly due to the enhanced temperature of $\sim 300^{\circ} \mathrm{C}$ recorded during implantation (Rehn et al 1985). Under the effect of ion bombardment, enhanced migration of impurity oxygen atoms inward and of iron and nickel atoms outward from the bulk leads to an iron-oxide, nickel-oxide rich zone near the surface of the sample. Chromium, although having a higher affinity for oxygen, is able to diffuse less than iron (Cox et al 1972) and therefore remains underneath the iron oxide and nickel-oxide rich outer layer. The presence of a carbon peak at the surface has been attributed to system contamination which depends on the target chamber pressure and the type of vacuum pump used for creating the vacuum in the target chamber.

Figure 3(a-e) shows the XPS spectra of $\mathrm{B}(1 s), \mathrm{O}(1 s), \mathrm{Cr}(2 p), \mathrm{Fe}(2 p)$ and $\mathrm{Ni}(2 p)$ levels of a ${ }^{11} \mathrm{~B}^{+}$implanted sample which was etched using $\mathrm{Ar}^{+}$ion sputtering to $385 \mathrm{~nm}$ to reveal the plateau region where maximum concentration of boron has been observed by the AES as shown in figure 2. Table 1 shows the core level binding energies (BE) of $\mathrm{B}, \mathrm{O}, \mathrm{Cr}, \mathrm{Fe}$ and $\mathrm{Ni}$ for the implanted sample along with other $\mathrm{BE}$ values taken from the literature (Wagner et al 1980; Briggs and Seah 1983). Figure 3a 


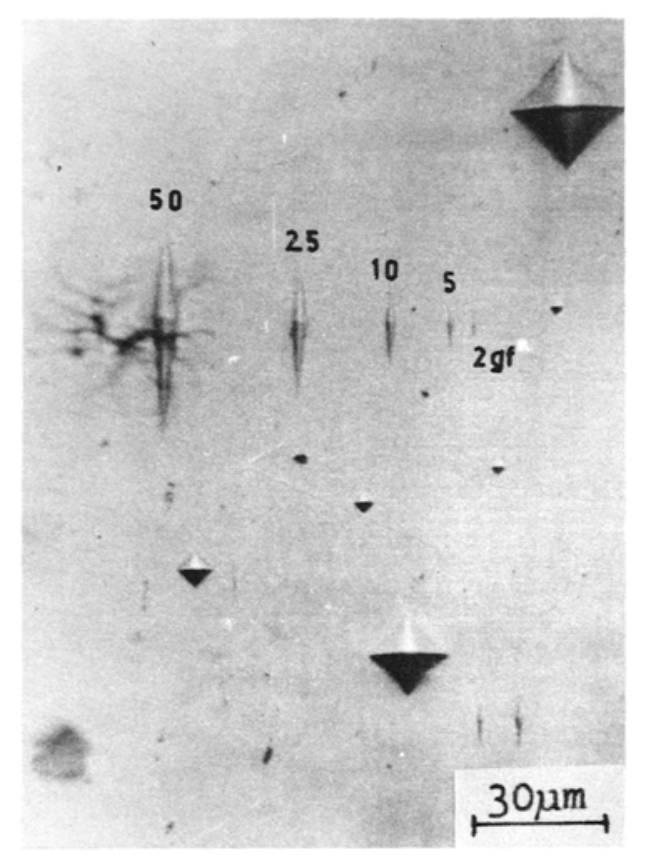

Figure 1. Optical micrograph shows surface of mechanically polished implanted specimen with ${ }^{11} \mathrm{~B}^{+}$ions and Knoop indentation marks at 2,5,10,25 and $50 \mathrm{gf}$.

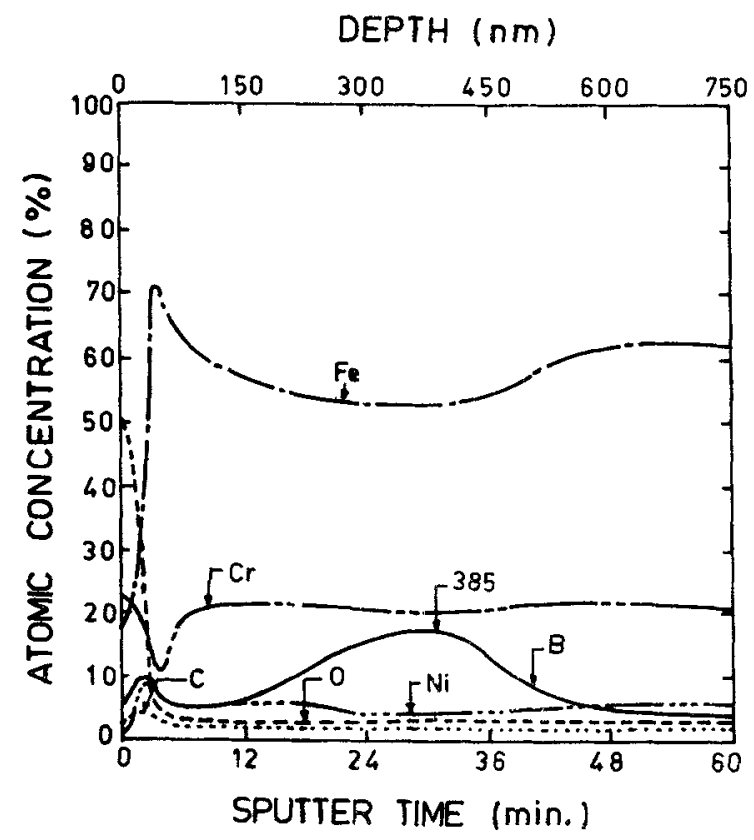

Figure 2. AES depth profile for 304 SS implanted with $2.5 \times 10^{1711} \mathrm{~B}^{+} \mathrm{cm}^{-2}$ at $130 \mathrm{keV}$. 


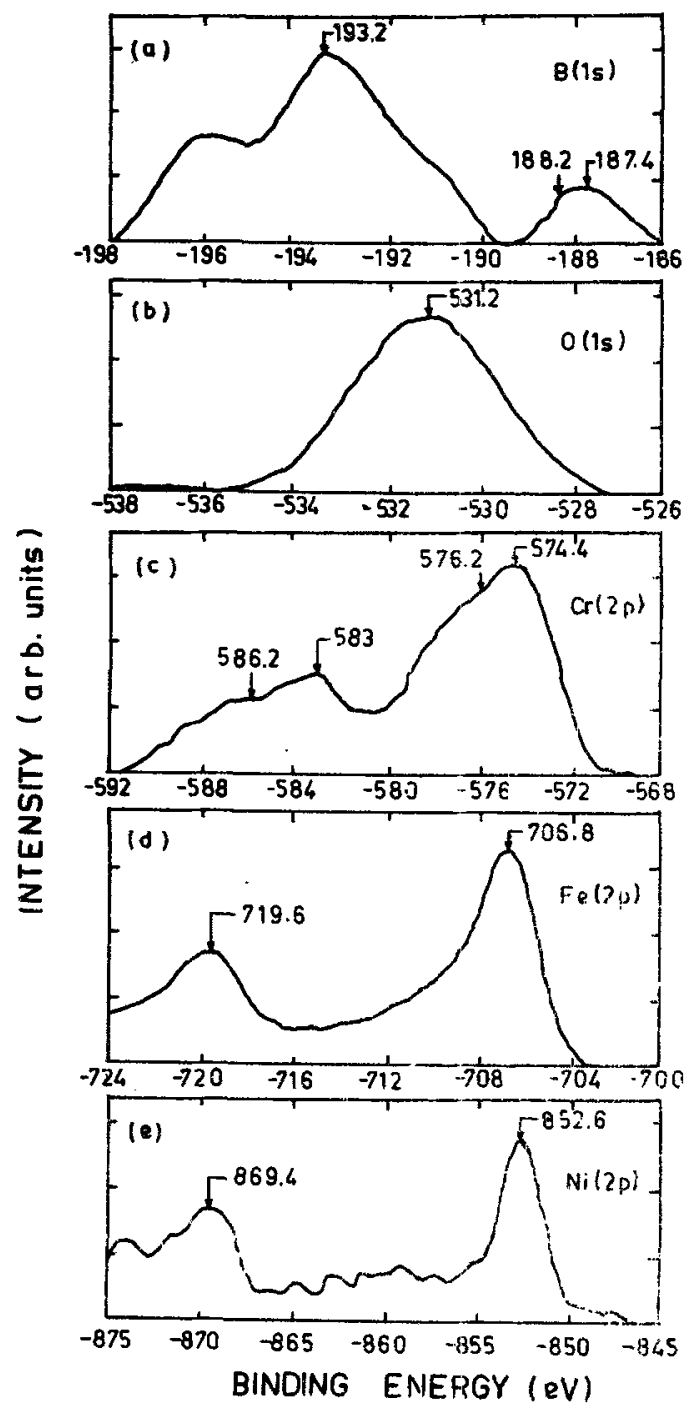

Figure 3. XPS spectra recorded at the plateau region of ${ }^{11} \mathrm{~B}^{+}$implanted 304 SS for (a) $\mathrm{B}(1 s)$, (b) $\mathrm{O}(1 s),(\mathrm{c}) \mathrm{Cr}(2 p)$, (d) $\mathrm{Fe}(2 p)$ and (e) $\mathrm{Ni}(2 p)$.

shows that for $\mathrm{B}(1 \mathrm{~s})$, three peaks appear at $187 \cdot 4,188.2$ and $193.2 \mathrm{eV}$ corresponding to metallic boron, $\mathrm{Fe}_{2} \mathrm{~B}$ and $\mathrm{B}_{2} \mathrm{O}_{3}$ compounds respectively (Wagner et al 1980). Figure $3 \mathrm{~b}$ shows that for $\mathrm{O}(1 \mathrm{~s})$, the peak appearing at $531.2 \mathrm{eV}$ perhaps corresponds to $\mathrm{B}_{2} \mathrm{O}_{3}$. Earlier, no such peak corresponding to $\mathrm{B}_{2} \mathrm{O}_{3}$ in the case of $\mathrm{O}(1 \mathrm{~s})$ spectra has been reported (Wagner et al 1980; Briggs and Seah 1983). The plateau region in figure 2 shows that the atomic concentration of oxygen is only about $3 \%$, so the only possibility is that $\mathrm{B}_{2} \mathrm{O}_{3}$ compound has been formed with some fraction of iron and chromium oxides and the possibility of $\mathrm{NiO}$ is negligible as evident from figure $3 \mathrm{e}$. Figure $3 \mathrm{c}$ shows that for $\operatorname{Cr}\left(2 p_{3 / 2}\right)$, two peaks appear at 574.4 and $576.2 \mathrm{eV}$ corresponding to $\left(\mathrm{Cr}\right.$ and $\left.\mathrm{CrB}_{2}\right)$ and $\mathrm{CrO}_{2}$ compounds (Wagner et al 1980). Figure 3d shows that for $\mathrm{Fe}\left(2 p_{3 / 2}\right)$, the peak appears at $706.8 \mathrm{eV}$ corresponding to $\left(\mathrm{Fe}, \mathrm{Fe}_{2} \mathrm{~B}\right.$ 
Table 1. Core level $\mathrm{BE}$ (in $\mathrm{eV}$ ) of various elements.

\begin{tabular}{|c|c|c|c|c|c|c|}
\hline \multicolumn{2}{|c|}{ Substance (reference) } & $\mathrm{Fe}\left(2 p_{3 / 2}\right)$ & $\mathrm{B}(1 s)$ & $\operatorname{Cr}\left(2 p_{3 / 2}\right)$ & $\mathrm{O}(1 s)$ & $\mathrm{Ni}\left(2 p_{3 / 2}\right)$ \\
\hline \multicolumn{2}{|c|}{$\begin{array}{c}304 \mathrm{SS}, 2.5 \times 10^{17{ }^{11} \mathrm{~B}^{+} \mathrm{cm}^{-2}} \\
\text { (from figure 3) }\end{array}$} & $706 \cdot 8$ & $193 \cdot 2,188 \cdot 2,187 \cdot 4$ & $576 \cdot 2,574 \cdot 4$ & $531 \cdot 2$ & $852 \cdot 6$ \\
\hline $\mathrm{Fe}$ & (Wagner et al 1980) & $706 \cdot 8$ & - & - & - & - \\
\hline $\mathrm{FeO}$ & (Wagner et al 1980) & $709 \cdot 3$ & - & - & $530 \cdot 1$ & - \\
\hline $\mathrm{Fe}_{2} \mathrm{O}_{3}$ & (Wagner et al 1980) & $710 \cdot 7$ & - & - & $530 \cdot 1$ & - \\
\hline $\mathrm{Fe}_{2} \mathrm{~B}$ & (Wagner et al 1980) & $706 \cdot 6$ & $188 \cdot 2$ & - & - & - \\
\hline $\mathrm{FeB}$ & (Briggs and Seah 1983) & 706.9 & - & - & - & - \\
\hline B & (Wagner et al 1980) & - & $187 \cdot 1$ & - & - & - \\
\hline $\mathrm{B}_{2} \mathrm{O}_{3}$ & (Wagner et al 1980) & - & $193 \cdot 1$ & - & - & - \\
\hline $\mathrm{Cr}$ & (Wagner et al 1980) & - & - & 574.1 & - & - \\
\hline $\mathrm{CrB}_{2}$ & (Wagner et al 1980) & - & - & $574 \cdot 2$ & - & - \\
\hline $\mathrm{CrO}_{2}$ & (Wagner et al 1980) & - & - & $576 \cdot 1$ & $530 \cdot 1$ & - \\
\hline $\mathrm{Cr}_{2} \mathrm{O}_{3}$ & (Wagner et al 1980) & - & - & $576 \cdot 6$ & $530 \cdot 3$ & - \\
\hline $\mathrm{Ni}$ & (Briggs and Seah 1983) & - & - & - & - & $852 \cdot 6$ \\
\hline $\mathrm{NiO}$ & (Briggs and Seah 1983) & - & - & - & $530 \cdot 2$ & $854 \cdot 1$ \\
\hline
\end{tabular}

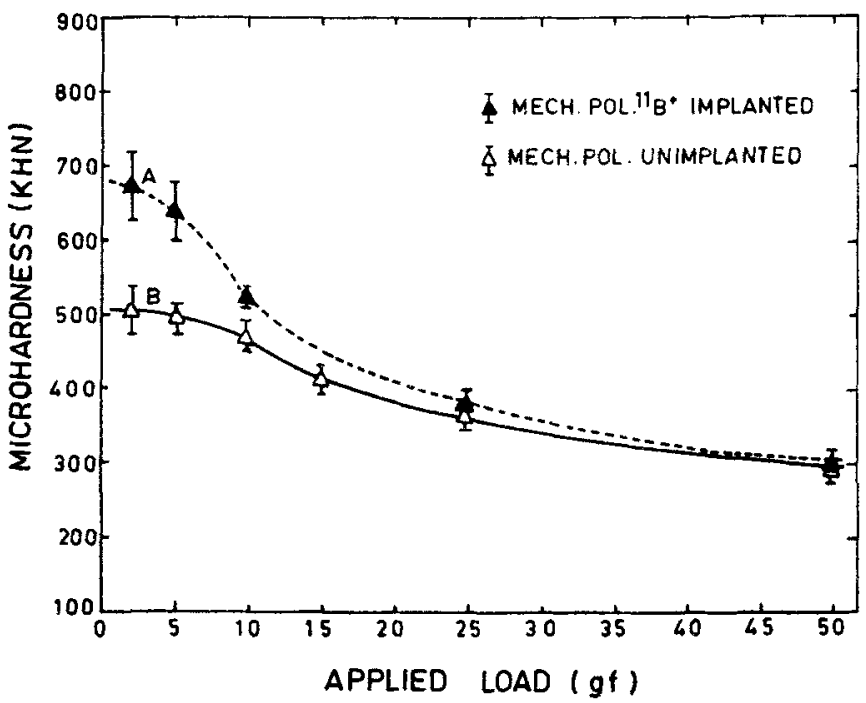

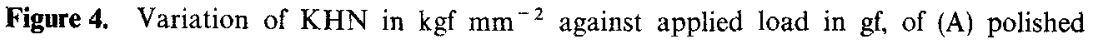
implanted and (B) polished unimplanted surfaces with ${ }^{11} \mathrm{~B}^{\top}$ ions at $130 \mathrm{keV}$ to a fluence of $2.5 \times 10^{17}$ ions $\mathrm{cm}^{-2}$.

and FeB) compound formation (Wagner et al 1980; Briggs and Seah 1983). A shift of $\pm 0.2 \mathrm{eV}$ was too small to be unambiguously detected in our XPS spectrometer. Figure $3 \mathrm{e}$ shows that for $\mathrm{Ni}\left(2 p_{3 / 2}\right)$, the peak appears at $852.6 \mathrm{eV}$ corresponding to metallic nickel (Briggs and Seah 1983).

The effect of ${ }^{11} \mathrm{~B}^{+}$ion implantation on the near-surface microhardness of mechanically polished and etched samples is shown in figures 4 and 5 as a function of applied load and in figure 6 as a function of depth of indentation corresponding to different loads respectively. The depth of indentation gives a semi-quantitative evaluation of the flow behaviour of the implanted layer. Curve B in figures 4 and 
6 are due to mechanically polished unimplanted samples. The microhardness near the surface is higher which may be attributed to the appearance of $\alpha_{b c c}^{\prime}$-martensite phase (Cavalleri et al 1986; Leutenecker et al 1989; Raud et al 1989) and the strained layer formed during mechanical polishing at the surface. These layers are subsequently removed upon etching and microhardness decreases as shown by curves $B$ and $D$ in figures 5 and 6 respectively.

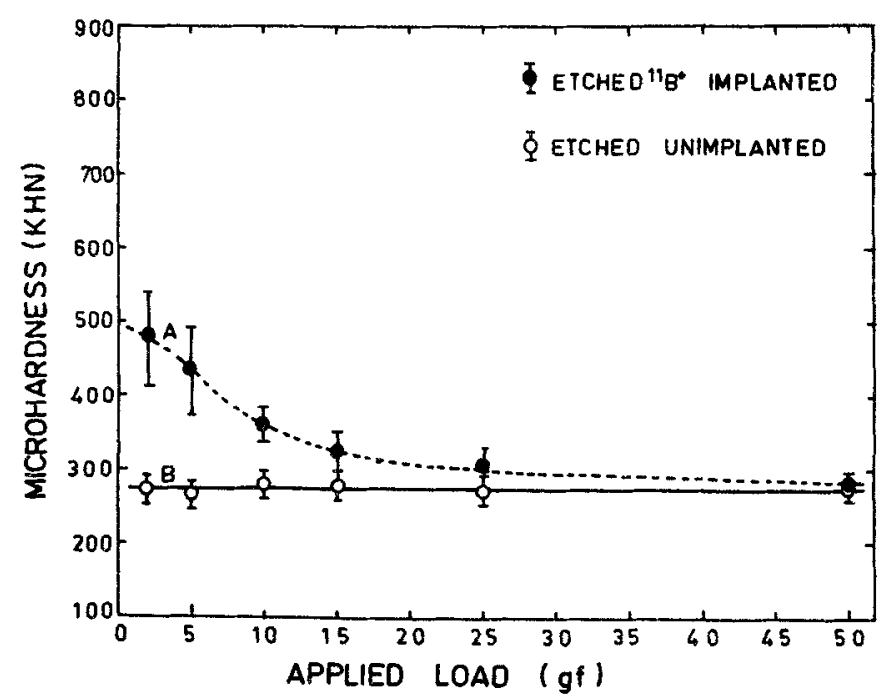

Figure 5. Variation of $\mathrm{KHN}$ in $\mathrm{kgf} \mathrm{mm}^{-2}$ against applied load in $\mathrm{gf}$, (A) etched implanted, and (B) etched unimplanted surfaces, with ${ }^{11} \mathrm{~B}^{+}$ions at $130 \mathrm{keV}$ to a fluence of $2.5 \times 10^{17}$ ions $\mathrm{cm}^{-2}$.

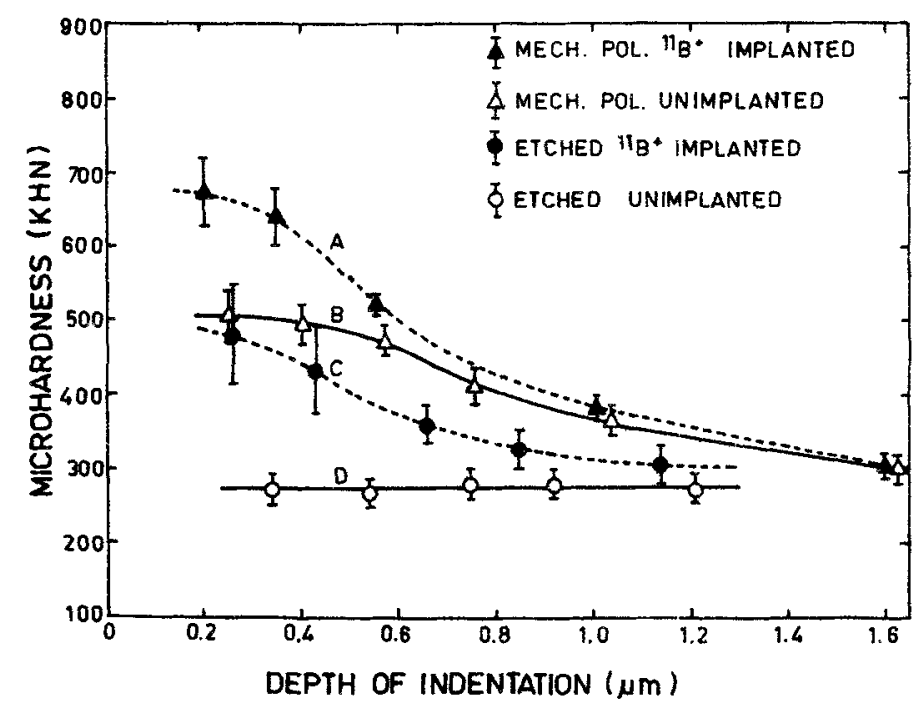

Figure 6. Variation of $\mathrm{KHN}$ in $\mathrm{kgf} \mathrm{mm}^{-2}$ against depth of indentation in $\mu \mathrm{m}$, of (A) polished implanted, (B) polished unimplanted, (C) etched implanted and (D) etched unimplanted surfaces. 


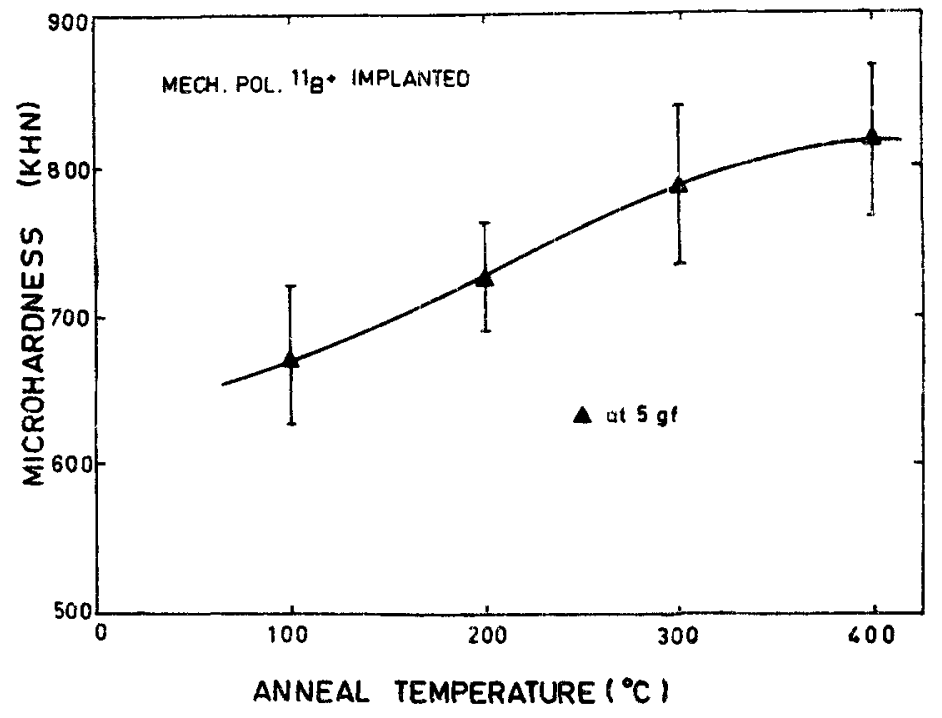

Figure 7. Variation of Knoop microhardness with annealing temperature for the mechanically polished ${ }^{11} \mathrm{~B}^{+}$implanted specimen. The annealing time is $4 \mathrm{~h}$ at each temperature.

From figures 4 and 5 , it is observed that ${ }^{11} \mathrm{~B}^{+}$implantation increases the microhardness at $2 \mathrm{gf}$ load by about $30 \%$ in the case of mechanically polished samples and by $\sim 80 \%$ in the case of etched samples. As the load becomes higher, the probe depth of the indenter exceeds the depth of the implanted layer, resulting in a large contribution of the substrate to the apparent hardness. It is for this reason, as seen from figure 6 , the hardness values fall to that of the unimplanted sample with increase in depth of indentation corresponding to different applied loads.

Boron is interstitial in $304 \mathrm{SS}$, so its implantation produces solid solution hardening. Additional strengthening mechanisms become effective at high doses, which are associated with the formation of boride compounds. $\mathrm{Fe}_{2} \mathrm{~B}$ and other borides of iron are also formed (Hohmuth et al 1983). By XPS analysis we observe that $\mathrm{B}_{2} \mathrm{O}_{3}, \mathrm{Fe}_{2} \mathrm{~B}$ and $\mathrm{CrB}_{2}$ compounds with some amounts of chromium oxides have been formed in the implanted layer as discussed earlier. These hinder the motion of fresh dislocations created during indentation and thus cause a change in the microhardness of the mechanically polished-implanted and etched-implanted samples. Boron implantation in 304 SS changes the austenite $\left(\gamma_{f c c}\right)$ to a martensite $\left(\alpha_{b c c}^{\prime}\right)$ phase (Raud et al 1989) which also contributes to this increased hardness.

Figure 7 shows the increase in microhardness at 5 gf of mechanically polished ${ }^{11} \mathrm{~B}^{+}$ implanted sample with increase in annealing temperature. With the increase of annealing temperature more boron diffuses to greater depths. This enhanced diffusivity of boron possibly causes change in the additional austenite to martensite phase (Raud et al 1989) and is responsible for the increase of hardness. 


\section{Conclusions}

It is observed that the strain-free surface of 304 stainless steel shows an increase in microhardness by $\sim 80 \%$ after high dose boron ion implantation at $2 \mathrm{gf}$ while the strained surface shows an increase of only $\sim 30 \%$ at the same load. At higher load values the contribution from the substrate to the apparent hardness becomes larger and it is for this reason (figure 6) that the hardness values fall to that of the unimplanted sample.

The characterization of the implanted layer using AES shows that the boron implantation profile in 304 stainless steel is about $750 \mathrm{~nm}$ deep with a peak atomic concentration of $\sim 17$ at. $\%$ at $\sim 385 \mathrm{~nm}$. Therefore the implanted sample was etched using $\mathrm{Ar}^{+}$ion sputtering to $\sim 385 \mathrm{~nm}$ to reveal the plateau region where the maximum concentration of boron occurs. XPS spectra show that boron, which is interstitial in 304 stainless steel, after implantation produces compounds as discussed in the text. This compound formation hinders the motion and generation of fresh dislocations, thereby, causing an increase in the microhardness of the strained-implanted and strain-free implanted samples. It is concluded that boron implantation in 304 stainless steel changes the austenite $\left(\gamma_{f c c}\right)$ to a martensite $\left(\alpha_{b c c}^{\prime}\right)$ phase which also contributes to increased hardness.

Mechanically polished boron-implanted samples were annealed separately at different temperatures. It is found that the microhardness at $5 \mathrm{gf}$ increases with the increasing annealing temperatures. It is observed that higher the annealing temperature the larger the boron diffusion to greater depths. This enhanced diffusivity of boron changes the additional austenite to a martensite phase and is responsible for the increase of hardness.

\section{Acknowledgements}

The authors are grateful to Dr Amitabh Jain and Dr Ami Chand, Indian Institute of Technology, New Delhi, for providing the ion implantation facilities and to Prof. L K Malhotra, Indian Institute of Technology, New Delhi, for the liberal use of AES and XPS analysis facilities.

\section{References}

Briggs D and Seah M P (eds.) 1983 Practical surface analysis by Auger and X-ray photoelectron spectroscopy (New York: John Wiley and Sons Ltd)

Cavalleri A, Guzman L, Ossi P M and Rossi I 1986 Scr. Met. 2037

Cox M G C, Mc Enancy B and Scott V D 1972 Philos. Mag. 26839

Dearnaley G 1985 Nucl. Instrum. Methods Phys. Res. B7/8 158

Goel A K, Sharma N D, Mohindra R K and Ghosh P K 1988 Indian J. Phys. A62 401

Goel A K, Sharma N D, Mohindra R K and Ghosh P K 1989a Indian J. Phys. A63 494

Goel A K, Sharma N D, Mohindra R K, Aggarwal S and Ghosh P K 1989b Indian J. Phys. A63 777

Hayashi N, Sakamoto I and Takahashi T 1984 J. Nucl. Mater. 128/129 756

Hayashi N and Takahashi T 1982 Appl. Phys. Lett. 411100

Hohmuth K, Rauschenbach B, Kolitsch A and Richter E 1983 Nucl. Instrum. Methods 209/210 249

Johnson E, Johansen A, Sarholt, Kristensen L, Roy-Poulsen H and Christiansen A 1985 Nucl. Instrum. Methods Phys. Res. B7/8 212 
Johnson E, Littmark U, Johansen A and Christodoulides C 1982 Philos. Mag. A45 803

Kluge A, Langguth K, Ochsner R, Kobs K and Ryssel H 1989 Mater. Sci. Eng. A115 261

Knystautas E J, Singh A and Fiset M 1987 Nucl. Instrum. Methods Phys. Res. B19/20 213

Leutenecker R, Wagner G, Louis T, Gonser U, Guzman L and Molinari A 1989 Mater. Sci. Eng. A115 229

Madakson P B 1985 Mater. Sci. Eng. 69167

Raud S, Garem H, Naudon A, Villain J P and Moine P 1989 Mater. Sci. Eny. A115 245

Rehn L E, Averback R S and Okamoto P R 1985 Mater, Sit. Eng. 691

Wagner C D, Riggs W M, Davis L E, Moulder J E and Muilenberg G E (eds.) 1980 Handbook of XPS (New York: Parkin-Elmer) 